\title{
ESTUDANTES INDÍGENAS NO ENSINO SUPERIOR E OS IMPASSES DE UMA CIDADANIA AFIRMATIVA
}

\section{INDIGENOUS STUDENTS IN HIGHER EDUCATION AND THE IMPASSES OF AN AFFIRMATIVE CITIZENSHIP}

\section{ESTUDIANTES INDÍGENAS EN LA ENSEÑANZA SUPERIOR Y LOS OBSTÁCULOS DE UNA CIUDADANÍA AFIRMATIVA}

Eduardo Harder

Doutor em Direito

Universidade Federal do Paraná

eduardoharder@ufpr.br

Ana Elisa de Castro Freitas

Doutora em Antropologia Social

Universidade Federal do Paraná

anaelisa@ufpr.br

Brasil

\section{Resumo}

Uma nova geração de estudantes indígenas universitários vive no Brasil as contradições na execução de políticas públicas que, na origem, reconhecem direitos humanos de caráter étnico e suas interfaces com ações que visam a equidade social e a justiça. Embora o ordenamento jurídico democrático do país, instituído pela Constituição Federal em 1988, preveja tais direitos, nas rotinas administrativas das universidades nacionais residem práticas que reiteram a integração e a redução das alteridades indígenas a padrões genéricos e hegemônicos presentes na sociedade envolvente. Em 2006, o jurista estadunidense de origem nipônica Kenji Yoshino resgata a noção de covering, cunhada originalmente por Erving Goffman em suas notas sobre estigma e identidade, para refletir sobre os processos de "encobrimento" de alteridades emergentes frente a estruturas estereotipantes. No presente estudo buscamos lançar um olhar sobre o fenômeno de reiteração das práticas coloniais de integração de indígenas à sociedade nacional brasileira focalizando-o a partir de uma análise de casos de covering recorrentes no cotidiano das universidades.

Palavras-chave: Povos Indígenas; Ensino Superior; Covering; Cidadania Afirmativa. 


\begin{abstract}
A new generation of indigenous university students in Brazil the contradictions in the execution of public policies that, recognize human rights of ethnic character and its interface with actions that aim at social equity and justice. Although the country's democratic legal system, established by the Federal Constitution in 1988, foresees such rights, in the administrative routines of national universities there are practices that reiterate the integration and reduction of indigenous alterities to generic and hegemonic patterns present in the surrounding society. In 2006, Japanese jurist Kenji Yoshino rescues the notion of covering, originally coined by Erving Goffman in his notes on stigma and identity, to reflect on the processes of "concealment" of emerging alterities versus stereotyped structures. In the present study we seek to look at the phenomenon of reiteration of the colonial practices of integration of indigenous people into the Brazilian national society, focusing on an analysis of recurrent covering cases in the daily life of universities.
\end{abstract}

Key words: Indigenous people; Higher education; Covering; Affirmative action

\title{
Resumen
}

Una nueva generación de estudiantes indígenas universitarios vive en Brasil las contradicciones en la ejecución de políticas públicas que, en el origen, reconocen derechos humanos de carácter étnico y sus interfaces con acciones que apuntan a la equidad social y la justicia. Aunque el ordenamiento jurídico democrático del país, instituido por la Constitución Federal en 1988, prevea tales derechos, en las rutinas administrativas de las universidades nacionales residen prácticas que reiteran la integración y la reducción de las alteridades indígenas a niveles genéricos y hegemónicos presentes en la sociedad circundante. En 2006, el jurista estadounidense de origen nipón Kenji Yoshino rescata la noción de covering, acuñada originalmente por Erving Goffman en sus notas sobre estigma e identidad, para reflexionar sobre los procesos de "encubrimiento" de alteridades emergentes frente a estructuras estereotipantes. En el presente estudio buscamos una mirada sobre el fenómeno de reiteración de las prácticas coloniales de integración de indígenas a la sociedad nacional brasileña, enfocándolo a partir de un análisis de casos de covering recurrentes en el cotidiano de las universidades.

Palabras-clave: Pueblos indígenas; Enseñanza superior; Covering; Ciudadanía afirmativa 


\section{Introdução}

cena se repete invariavelmente
com grande constrangimento:
uma jovem mãe indígena é proibida de ingressar com seus colegas estudantes no ônibus da universidade para uma atividade pedagógica por estar acompanhada de sua filha recém-nascida. Não raro é orientada a se retirar do veículo, sendo conduzida pelo motorista, sob o olhar dos demais passageiros não indígenas.

Os argumentos para constrangimentos dessa natureza remetem, em regra, a fundamentos jurídicos. $\mathrm{Na}$ situação narrada acima, os agentes públicos afirmam que somente indivíduos com vínculo jurídico institucional estatal comprovado poderiam utilizar o transporte oficial. A comprovação de vínculo, nesse caso, é aferida individualmente dos passageiros mediante apresentação do registro de matrícula de estudante ou servidor da universidade. As rotinas previstas legalmente são de caráter individualizantes e seguem um roteiro fixado na década de $1950^{1}$, aplicado desde um padrão formal, universalista e anacrônico.

$\mathrm{O}$ ingresso de estudantes indígenas nas universidades brasileiras introduz um

1 Consultar, no caso, o texto da Lei Federal n. 1.081 , de 13 de abril de 1950, que dispõe no Brasil sobre o uso de carros oficiais, exarada no governo do General Eurico Gaspar Dutra (19461951). impasse nessa perspectiva individual, prevista nos ordenamentos vigentes supracitados. A pessoa ameríndia, reconhecida em sua alteridade, desde um perspectivismo ontológico (VIVEIROS DE CASTRO, 1996), remete ao campo dos denominados direitos coletivos. Essa natureza de direitos prevê o reconhecimento de sujeitos que transcendem a perspectiva do indivíduo moderno, por se constituírem ontologicamente na relação indissociável com uma coletividade de pertencimento, verificável materialmente em diferentes escalas socio-organizacionais - povo, comunidade, rede de parentesco, família, mãe e filhos.

Essa cosmogonia ameríndia que orienta ontologicamente pessoas com origem étnica diferenciada - inclusive nas relações entre mães e pais e seus filhos pequenos ou mesmo em estágio de amamentação - parece não constituir elemento válido e eficaz para reorientar uma velha diretriz da administração pública brasileira implementada pelas universidades e seus órgãos de controle externo.

Concretamente, uma jovem geração de estudantes indígenas universitários vive no Brasil um cotidiano de efetivação dos direitos étnicos e, ambiguamente, a permanência de ordenamentos que reiteram padrões universalistas nas instituições. 
Sobre esses padrões, são acrescidos valores arraigados a preconceitos e estigmas, próprios da história das relações coloniais. Tais situações impactam o cotidiano acadêmico de estudantes com diferentes origens étnicas, de gênero, opção sexual, religiosas, linguísticas etc. $\mathrm{O}$ reconhecimento da diversidade e da pluralidade constituintes da nação fica pairando como um horizonte ideal, longe de ser plenamente efetivado no plano material, e o caminho é longo.

O presente ensaio discorre sobre renitentes contradições na execução de políticas públicas de ação afirmativa que, em sua origem, reconhecem direitos humanos que visam garantir a equidade social e realização de um ideal de justiça no ensino superior brasileiro (DWORKIN, 2011). A narrativa é composta desde a experiência administrativa e acadêmica dos autores, cujas ações e apontamentos buscam não somente estabelecer o necessário olhar crítico, mas também colaborar no processo de transformação e aperfeiçoamento institucional em processos de ingresso e permanência de estudantes indígenas em uma universidade pública.

Embora o ordenamento jurídico democrático do país instituído pela Constituição Federal brasileira em 1988 preveja a aplicabilidade e eficácia imediata dos direitos fundamentais, nas rotinas administrativas das universidades nacionais persistem práticas que reiteram um ideal colonial de integração e redução das alteridades indígenas a padrões genéricos e hegemônicos presentes na sociedade nacional.

O exame dessa problemática é ancorado na análise de casos etnográficos registrados pelos autores no cotidiano da Universidade Federal do Paraná (UFPR), entre os anos de 2006 e 2018. No percurso analítico, busca-se um diálogo com os conceitos de passing e covering, apresentados jurista Kenji Yoshino (2006), para refletir sobre os processos de acobertamento e encobrimento de identidades emergentes frente a estruturas estereotipantes.

\section{Preâmbulo}

Revisitando notas de campo, diários de classe, pareceres e relatórios institucionais, a leitura remete a uma natureza de registro que se poderia situar entre o memorialístico e o registro de época. O caráter das notas pessoais agrega aos fragmentos de eventos históricos relatados um plano significativo. Está-se diante de um conjunto de narrativas entremeadas com reflexões ainda inconclusas. Evocando Tim Ingold (2015) se poderia qualificar tais registros como narrativas vivas, cujos filamentos e fluxos estão em aberto. $\mathrm{O}$ texto entrelaça fragmentos etnográficos de entrevistas realizadas com estudantes 
indígenas e as memórias de cenas presenciadas pelos docentes autores, aproximando sujeitos históricos de diferentes pertencimentos que encontram na universidade pública um espaço comum de vida cotidiana, compartilhando espaço ativo em tempos de reconhecimento e afirmação dos direitos humanos no Brasil.

Sujeitos cujas biografias envolvem sua participação na sociedade civil em ações que visam a democratização das relações sociais e a crítica à desigualdade que persiste nessa sociedade. Sujeitos que ingressam na carreira acadêmica nacional como docentes pesquisadores ou como estudantes, vivenciando uma universidade pública cujos desígnios dialogam com o ideal de transformação substancial nos processos de ingresso e pertencimento institucional.

São centenas de instituições de ensino superior federais, estaduais e/ou comunitárias brasileiras que estabelecem procedimentos diferenciados para $\mathrm{O}$ ingresso e permanência de estudantes oriundos de escolas públicas, negros, indígenas, com necessidades especiais, migrantes e refugiados nas primeiras décadas do século XXI.

Trata-se de uma ação transformadora da composição acadêmica das universidades brasileiras. Uma geração de graduados, mestres e doutores confere novos ares a antigas e jovens instituições do sistema universitário público. Tal processo não transcorre sem conflitos, resistências, discussões intensas, inclusive na Corte Constitucional sobre a legalidade (reconhecida) dos processos relacionados às denominadas políticas de ação afirmativa.

Os autores são professores e pesquisadores na Universidade Federal do Paraná, uma centenária instituição localizada na região sul do país. Atuam há mais de uma década nos processos de ingresso e permanência de estudantes indígenas provenientes de diferentes etnias que compõem a sociodiversidade relacionada a povos indígenas no Brasil (CUNHA, 2012). Essa atuação abrange a participação em instâncias administrativas responsáveis pela execução da política pública e a docência, através de projetos de extensão, pesquisa e ensino (FREITAS E HARDER，2010，2013a; 2013b; 2018; FREITAS, 2015a; 2015b).

As situações narradas e testemunhadas pelos autores constituem o substrato desse ensaio. São situações cotidianas que condensam uma dimensão significativa da vida social, por explicitarem e tornarem sensível a cena cotidiana, evidenciando os atores em suas posições recíprocas, durante eventos marcantes. Cenas semelhantes foram focalizadas por Erving Goffman (2002) em seus estudos sobre os dramas da vida cotidiana, nos quais sujeitos são postos em perspectiva, figurando como personagens/atores, e se veem às 
voltas com os impasses dos jogos de representação de si na relação com os outros.

As cenas aqui revisitadas - substrato material da análise - são recompostas a partir dos fragmentos narrativos dos sujeitos que as vivenciaram, embasadas nos registros de entrevistas recolhidas diretamente pelos autores, muitas delas remetendo a cenas igualmente presenciadas. Passados os anos, suas reminiscências preservam o gosto amargo dos eventos que marcam negativamente a experiência de vida de seus sujeitos/personagens protagonistas. São potentemente reveladoras dos limites programáticos de ideais de transformação social frente à crueza da vida cotidiana - cuja dramática reitera situações de desigualdade, assimetria de poder, silenciamento e impotência de jovens estudantes indígenas frente à imposição de rotinas administrativas em que sobressaem hierarquias sociais de um passado colonial e autoritário, que busca integrar com violência diferenças étnicas, ontológicas, de gênero, linguísticas, sociais, em unidades hegemônicas totalitárias.

A memória de eventos dolorosos de discriminação negativa, relacionados ao estigma de ser indígena no Brasil, é parte constituinte da experiência de vida da quase totalidade de jovens indígenas que ingressam nas universidades públicas brasileiras. Especialmente nas cidades da região sul do país, tais como Curitiba, onde se situam os campi-sede da Universidade Federal do Paraná, a condição indígena torna-se relativamente mais diacrítica na vida cotidiana se comparada às cidades das regiões norte e nordeste do país, em que a história de branqueamento não observou a mesma tônica.

Sucessivas frentes de colonização europeia, envolvendo imigrantes de origem alemã, polonesa e italiana, sobre uma camada de colonização portuguesa pretérita, definiram desde a segunda década do século XIX uma estrutura fundiária na qual a propriedade da terra e os ideais de desenvolvimento e progresso estão correlacionados no imaginário nacional aos imigrantes brancos, em que pese o reconhecimento da ocupação originária indígena, por sua vez associada por esse mesmo imaginário aos fatores de entrave ao desenvolvimento.

Os jovens indígenas que ingressam na universidade carregam paradoxalmente a marca de situações dolorosas de exclusão e violência, humilhação e desconsideração de suas capacidades, vivenciadas nas ruas, mercados, escolas públicas que frequentaram, ainda crianças, nas pequenas cidades do entorno das terras indígenas, e a expectativa de encontrar a justiça no cotidiano das universidades (JACINTO DA ROSA, 2015). A ideia de universidade, no imaginário desses jovens indígenas, é correlacionada ao ideal de justiça e equidade 
(DWORKIN， 2011; SANDEL， 2011), horizonte institucional em que suas diferenças são elevadas à condição de valor - ao invés de serem reiteradas como elementos desabonadores à plena fruição da vida social cotidiana. De modo geral, a universidade figura, na perspectiva desses estudantes indígenas, como espaço correlacionado a uma vida cotidiana mais tranquila, marcada pela convivência positiva junto aos colegas, professores, próprias de um ideal institucional republicano.

Muito cedo, entretanto, os jovens indígenas se deparam na cena cotidiana das universidades, nos corredores, elevadores, salas de aula, cantinas, bibliotecas, com situações que evocam as cenas preteritamente vivenciadas na infância, no interior das terras indígenas, ou nas cidades de entorno, marcadas pela assimetria de poder, desigual e violenta, da fricção interétnica (CARDOSO DE OLIVEIRA, 1972).

Quais os limites, quase invisíveis, das ações que reiteram (e reinventam) esse passado colonial nas relações cotidianas vivenciadas nas universidades? Quais são essas ações que condicionam e mitigam o potencial transformador do reconhecimento da diferença, presente nessa nova geração de direitos humanos? Quais as condutas adotadas pelos jovens indígenas quando o que está em jogo é a representação de si nessas cenas cotidianas? Este será o caminho percorrido no presente ensaio.

\section{Breve incursão a uma universidade pública brasileira}

Em todo o mundo, as grandes instituições de ensino superior podem ser caracterizadas como complexas estruturas administrativas, com maior ou menor autonomia em sua gestão e orçamento. A função social das universidades abrange desde a formação profissional, produção de novos conhecimentos, técnicas e tecnologias, prestação de serviços hospitalares, atuação nas áreas de arte e cultura etc. A Universidade Federal do Paraná (UFPR) não poderia ser diferente.

Fundada há mais de um século, em 1912, na cidade de Curitiba, a Universidade do Paraná (privada) foi federalizada (tornada pública) na década de 1950 e o atual arranjo institucional remonta aos marcos regulatórios nacionais. Sua atual estrutura administrativa departamental foi forjada no bojo da Reforma Universitária de 1968. Por sua vez, sua expansão para o interior do Paraná ocorreu fortemente em meados da década de 2000, em consonância ao cenário universitário nacional vinculados a programas de governo federal, tais como o Programa Expandir e o Programa Reuni.

A UFPR possui aproximadamente 30.000 estudantes de graduação e pósgraduação, 3.700 servidores técnico- 
administrativos e 2.700 docentes. $^{2}$ É uma instituição com ênfase regional, sendo uma das principais da região sul do país. Não obstante, no imaginário institucional prevalece uma presença ameríndia distante, sobretudo vinculada a longínquas Terras Indígenas e objeto de interesse aos estudos apenas de áreas como a linguística, antropologia, história e arqueologia. De fato, há uma tradição de estudos nesses campos de conhecimento, constituindo um inegável acervo da cultura material e imaterial dos povos originários americanos.

Nessa instituição, de história secular, vale notar que o ingresso de universitários indígenas teve início apenas em 2005, mediante a criação de vagas suplementares destinadas exclusivamente para estudantes pertencentes a povos indígenas cujos territórios se situem no Brasil. No plano administrativo, tal política é regulamentada através da Resolução 37/04 do Conselho Universitário, que institui o Plano de Metas de Inclusão Racial e Social na UFPR (FREITAS, 2015b).

Vagas suplementares configuram uma modalidade especial de vagas, excedentes àquelas de concorrência geral, destinadas exclusivamente para jovens indígenas que tenham concluído os estudos em nível médio e que desejem ingressar em carreiras convencionais na UFPR. O acesso

\footnotetext{
2 Dados de 2016, do relatório "UFPR em números" (www.proplan.ufpr.br).
}

dos indígenas às vagas suplementares ocorre por meio do Vestibular dos Povos Indígenas do Paraná, concurso realizado em conjunto com as universidades públicas do estado do Paraná ${ }^{3}$. É importante registrar que em quase um século de atividades são desconhecidos registros anteriores de presença acadêmica indígena na UFPR.

A implementação do Plano de Inclusão Racial e Social na UFPR incentivou indígenas de diferentes etnias e regiões do país a participar dos processos seletivos e estudar na universidade, e se insere no bojo das ações afirmativas (ZONINSEIN E FERES, 2008). Em pouco mais de uma década, o componente discente indígena presente na instituição podia-se caracterizar por uma diversidade étnica relativamente alta, embora a maioria do alunado pertença aos povos indígenas Kaingang e Guarani, cujos territórios estão na zona de influência da universidade, abrangendo as regiões sul e sudeste do país (FREITAS, 2015b).

Uma média anual de 50 jovens compõem o quadro de estudantes indígenas regularmente matriculados em distintos cursos de graduação na UFPR. São jovens,

\footnotetext{
${ }^{3}$ Desde 2012, o ingresso de estudantes indígenas na UFPR é também possibilitado mediante à concorrência a vagas de cotas, destinadas a indígenas pela Lei Federal 12.711 de 29 de agosto de 2012, que podem ser acessadas através dos processos seletivos vestibulares de entrada geral acadêmica. Além destas, há oferta de vagas específicas destinadas a jovens oriundos do meio rural, às quais os indígenas também podem apresentar-se. Para uma análise mais detalhada desse assunto, ver: Freitas e Harder (2013a; 2013b).
} 
homens e mulheres, que buscam a formação profissional em carreiras convencionais. São estudantes pertencentes a mais de uma dezena de etnias diversas, advindos das cinco regiões do Brasil. Prioritariamente buscam a formação em cursos da área da saúde, historicamente frequentados quase exclusivamente por filhos de famílias representantes das elites sociais regionais, tais como Medicina, Odontologia, Fisioterapia, Enfermagem e Nutrição. Em segundo plano, buscam cursos das áreas de estudos jurídicos, das engenharias e ambientais, tais como Direito, Engenharia Civil, Arquitetura e Urbanismo, Agronomia, Biologia, Gestão Ambiental, Agroecologia, Geologia, Medicina Veterinária. Entre 2005 e 2018, cerca de 25 estudantes indígenas concluíram seus cursos de graduação na UFPR.

Ao longo de uma década, a universidade sofreu modificações em suas estruturas administrativas internas, constituindo unidades, conselhos e outras instâncias de acompanhamento dedicadas aos processos de ingresso e permanência dos estudantes indígenas na instituição. Instâncias colegiadas específicas, tais como o Núcleo Universitário de Educação Indígena (NUEI), o Comitê Gestor de Acompanhamento do Componente Indígena do Plano de Metas de Inclusão Racial e Social da UFPR (instância que conta com participação indígena e possui caráter deliberativo), o Grupo PET Litoral Indígena, na modalidade Conexões de Saberes, fomentado pelo Ministério da Educação e voltado à formação de intelectuais indígenas em alto nível no Brasil (FREITAS, 2015a), entre outros. Essas instâncias específicas atuam em conjunto e com outras de natureza geral presentes na universidade, tais como a Ouvidoria Geral, a Reitoria, as Pró-Reitorias, Coordenações de Curso, Restaurantes Universitários, Bibliotecas, etc.

Mediante o ingresso de estudantes indígenas, negros e oriundos de camadas populares, a função social da universidade brasileira sofreu rápidas transformações, mas as tensões e resistências étnicas, raciais e de classe vivenciadas na sociedade abrangente marcada pela desigualdade social, seguiram se reproduzindo no cotidiano institucional, especialmente nos cursos mais competitivos e elitizados (PALADINO e ALMEIDA, 2012). Preconceito, estigma, discriminação, violência simbólica são parte das cenas cotidianas vivenciadas pelos estudantes indígenas no interior das universidades, do mesmo modo que a compaixão ou a curiosidade pelo exótico também se verifica (NERES, 2017). Em síntese, a formulação de um novo horizonte institucional forjado em decorrência da implementação de políticas públicas de ação afirmativa não tem implicado automaticamente na ruptura com a herança de um passado colonial, o qual segue assombrando a experiência dos 
sujeitos dessas políticas e exigindo um permanente esforço descolonizador.

\section{Passing ou Covering? Quando é preciso acobertar ou encobrir a identidade}

Em decorrência da implementação de políticas de inclusão e ação afirmativa, podese observar no interior das distintas universidades públicas brasileiras a criação de um conjunto novas de estruturas administrativas dedicadas à formulação de rotinas e execução de práticas de recepção e acolhimento. Esse processo não é exclusivo do caso brasileiro, mas pode-se verificar em países que, tais como o México, possuem um histórico de políticas de educação superior direcionadas a componentes discentes etnicamente diferenciados. Nesse sentido, tais estruturas são próprias dos processos de institucionalização e efetivação de políticas de ação afirmativa de caráter étnico (AUPETIT, 2009). No entanto, seu repertório de encaminhamentos convive, nem sempre de modo pacífico, com rotinas e práticas já consolidadas no âmbito administrativo e jurídico institucional, alicerçadas em uma perspectiva universalista. As cenas a seguir talvez sintetizem melhor este choque cotidiano, o qual muitas vezes envolve discursos ambíguos.
Estamos na sala de reuniões de um prédio centenário, em um departamento administrativo da universidade. $\mathrm{O}$ agente público, investido de um cargo de alta responsabilidade, dirige-se aos estudantes indígenas: - "Ao ingressarem na UFPR vocês, estudantes indígenas, passam a ser como todos os demais estudantes. As diferenças são reconhecidas até o momento de ingresso. Aqui, vocês precisam se acostumar que são iguais aos outros".

O estranhamento é geral frente a uma afirmação que lança mão de um ideal universalista de isonomia (BOBBIO, 1996) para justificar a desconsideração das diferenças dos sujeitos receptores do discurso que, no caso, pleiteavam junto à administração universitária a adequação de critérios de rendimento acadêmico para fins da percepção de bolsas e auxílios. O tom e contexto discursivo resultavam objetivamente na negação das diferenças culturais, linguísticas, ontológicas, sociopolíticas que constituem as alteridades indígenas ali presentes.

O contexto da afirmação reflete um debate moral sobre meritocracia e isonomia, um discurso que reconhece as diferenças até o limite identitário abstrato ou imaterial, sem repercussões na esfera concreta da administração pública, por exemplo.

Uma boa parcela dos quadros técnicos e docentes da universidade ainda é tributária de sistemas de ensino cujos parâmetros éticos 
e técnicos espelham valores estranhos aos novos paradigmas filosóficos e jurídicos em debate. Assim, se a origem do estudante remete a um distante território indígena, uma paisagem camponesa ou à periferia industrial de um grande centro urbano, tudo isso deve ser esmaecido diante de critérios universais de vulnerabilidade socioeconômica, assiduidade e frequência, bom histórico acadêmico, com boas avaliações e dedicação integral e exclusiva aos estudos.

E aqui residem conflitos cotidianos de uma sutileza que transcende responsabilizações e processos administrativos disciplinares. Conflitos, por exemplo, relacionados ao calendário acadêmico. Vejamos outra cena.

Durante uma reunião que abrangeu a participação de representantes de todas as universidades do estado do Paraná que possuem políticas de ingresso e permanência voltadas a estudantes indígenas, tratava-se do estabelecimento de critérios para avaliar a adequação ou não do calendário acadêmico geral da universidade às especificidades sóciopolíticas dos estudantes indígenas. Diversos participantes relatavam casos de estudantes que exibiam períodos recorrentes de infrequência nos cursos, intercalados com períodos de frequência intensiva, correlacionando essa oscilação na permanência ao baixo rendimento acadêmico desses estudantes. Alternativamente, os estudantes justificavam que a infrequência resultava da necessidade de atender a compromissos sociais junto a seus coletivos indígenas. Discutia-se a proposição de institucionalizar um calendário especial para reger a vida acadêmica dos estudantes indígenas nas universidades ali reunidas.

Certa hora, uma professora pediu a palavra e argumentou que os estudantes de sua instituição estariam burlando os sistemas de controle de frequência acadêmica para colaborar no extrativismo de pinhão (Araucaria Angustifolia), entre meados dos meses de maio e junho. Houve uma grande reação dos estudantes indígenas presentes no auditório. Em que pese a manifestação de alguns estudantes, acrescidas da manifestação de docentes pesquisadores, argumentando que tais atividades constituem e atualizam obrigações recíprocas com seus povos e coletividades de pertencimento, sendo importantes para a educação tradicional da pessoa indígena e bem estar de sua vida social, o colegiado reunido deliberou que o calendário acadêmico dos estudantes indígenas permaneceria inalterado.

Ainda sobre as contradições das dinâmicas sociais indígenas frente às exigências dos calendários acadêmicos, vejamos este outro fragmento de notas. Um estudante pertencente à etnia Laklãnõ, cuja territorialidade está relacionada ao planalto norte do estado de Santa Catarina, viveu durante o período de graduação na UFPR um dilema: "Como atender aos compromissos 
exigidos em decorrência da função de juiz desempenhada junto ao povo indígena Laklãnõ e, igualmente, cumprir o regime de frequências às aulas e entrega de atividades curriculares exigidas pelo curso de graduação em Música na UFPR?” O dilema encerrado nessa situação foi narrado pelo próprio estudante laklãnõ à equipe responsável pelo setor administrativo de assistência estudantil da UFPR, após ser informado sobre a iminente suspensão do pagamento de suas bolsas de estudos e permanência, em decorrência de suas ausências reincidentes no curso de Música. A via argumentativa do estudante não produziu efeitos junto à coordenação do curso e, após alguns semestres, o caminho escolhido foi a evasão por desistência. Conciliar o importante papel jurisdicional junto a sua coletividade (uma autoridade) se revelou incompatível com o lugar social de estudante em uma universidade.

Focalizemos essa problemática desde outra perspectiva. A competitividade se revela como um componente naturalizado nas relações sociais acadêmicas, desde o ingresso nos processos seletivos, passando pela escolha das amizades e formação de grupos no interior das salas de aula. Isso se verifica com maior intensidade nos cursos mais elitizados. Um dos relatos mais comuns recolhidos junto aos estudantes indígenas ao longo dos anos, revela justamente a dificuldade em participar de trabalhos coletivos exigidos pelos professores. Muitos estudantes indígenas relatam que são preteridos pelos demais nos processos de constituição de grupos de estudos, precisando realizar os trabalhos sozinhos e se vendo privados de compartilhar os estudos com colegas:

$\mathrm{O}$ professor estabeleceu que o trabalho deveria ser realizado em grupos de dois ou três colegas e, a seguir, concedeu alguns minutos para que a turma se organizasse e formasse os grupos. Todos os grupinhos se formaram rapidamente, e logo me vi de fora e sozinho. Discretamente manifestei meu descontentamento ao professor, que rebateu dizendo que esse era um assunto nosso, dos estudantes; argumentou que na universidade não há mais crianças que exijam a mediação do professor para a constituição de grupos de estudo. Reiterei que não havia conseguido me inserir em nenhum grupo e questionei se seria possível a realização do trabalho individualmente. Diante da resposta negativa, recorri a sala com o olhar e localizei um outro estudante que geralmente também fica de fora dos grupos, porque costuma ser relapso no cumprimento das atividades. Diante da imposição do professor, restou-me compor o grupo com ele, fazendo toda a atividade sozinho. Me vi sobrecarregado, tendo que arrastar o colega relapso nas costas. (Relato do estudante A; caderno de notas pessoais dos autores). 
Inconformado com a situação, o estudante constata pesarosamente que, por mais que se empenhasse na dedicação aos estudos e cumprisse assiduamente com as responsabilidades de prazos e acordos realizados com professores e colegas, sua condição indígena era vista negativamente pelos pares na hora de compor grupos de estudos ou lazer, nos diversos ambientes do cotidiano acadêmico. Analisando a situação, o estudante teceu uma crítica construtiva, apontando uma mediação alternativa que poderia ter sido adotada pelo docente: "Ele [professor] poderia ter feito um sorteio para a composição dos grupos, o que seria mais justo, inclusivo, imparcial e impessoal".

Nos casos narrados fica implícita a constatação de que muitas vezes a melhor saída é acobertar (não revelar) a identidade indígena para evitar constrangimentos.

Vejamos esse outro caso, encaminhado para a Ouvidoria Geral da universidade e arquivado posteriormente, cujo fato gerador consistia no questionamento motivado por uma estudante indígena da área da saúde, dirigido a docente responsável por uma disciplina: - "Por que razão não poderia realizar as atividades laboratoriais como os demais colegas de turma, devendo assistir passivamente a essas práticas, posicionada ao lado de seus pares nas bancadas, sem acesso aos equipamentos?" A resposta da professora ancorava-se no argumento de que o número de lugares nas bancadas do laboratório comportaria somente estudantes aprovados no processo seletivo convencional, não havendo espaço para os estudantes excedentes, provenientes, por exemplo, de vagas suplementares com ingresso através do Vestibular dos Povos Indígenas do Paraná, os quais não teriam previsão de lugar.

O posicionamento da docente, destituído de fundamentos previstos nos ordenamentos vigentes na instituição, revelava um fundo axiológico que contrastava com os argumentos considerados válidos à perspectiva de uma estudante indígena cuja formação acadêmica incluía a participação ativa nas lutas por reconhecimento (HONNETH, 2003), o envolvimento nas agendas do movimento estudantil indígena em busca da efetivação dos direitos étnicos na universidade e na sociedade. A situação foi considerada pela estudante como "combustível motor" à superação das dificuldades e fortalecimento das metas de conclusão do curso, o que de fato aconteceu dois anos após o fato relatado.

A diversidade linguística ameríndia - embora idealisticamente valorizada pelas agendas culturais - não raro se constitui em barreira material intransponível para os estudantes indígenas que cursam graduação e pós-graduação nas universidades públicas brasileiras. Vejamos um caso. 
O desconhecimento de uma língua estrangeira para a leitura de textos e confecção de resenhas resultou na avaliação de baixo aproveitamento de um estudante indígena que, paradoxalmente, era exímio em sua língua originária materna ${ }^{4}$, aprendida antes da própria língua portuguesa. Segundo o estudante, o docente havia selecionado diversos textos para leitura obrigatória durante o semestre, a maior parte deles em línguas estrangeiras. Seu esforço em aprender uma nova língua esbarrava no tempo exíguo para a entrega das resenhas, por isso o baixo aproveitamento. Os colegas, provenientes em sua maioria de uma classe média urbana, já possuíam conhecimentos sobre línguas estrangeiras e ele se sentia constrangido em solicitar ajuda, preferindo encobrir-se e realizar as traduções solitariamente. Durante entrevista do autor com o professor responsável pela disciplina, este se mostrou surpreso: - "Em uma turma com 60 ou 70 estudantes não poderia imaginar que havia ali um estudante indígena! Muito menos que o referido estudante era bilíngue, sendo sua língua nativa materna outra que não a língua portuguesa!". Embora sensível ao caso, a informação não resultou em nenhuma alteração na prática docente do professor,

\footnotetext{
4 “Mais de 150 línguas e dialetos são faladas pelos povos indígenas no Brasil". Instituto Socioambiental.

(pib.socioambiental.org/pt/L\%C3\%ADnguas)
}

tais como a destinação de estudante-monitor para colaboração nas leituras, ou flexibilização dos prazos de entrega e formatos dos trabalhos exigidos. $\mathrm{O}$ estudante indígena, engajado nas frentes de representação estudantil em diferentes instâncias nacionais e internacionais, terminou evadindo da universidade.

Não raro, ao migrarem para as cidades nas quais se localizam as universidades, os estudantes indígenas viajam com suas famílias. Filhos, cônjuges e sua rede de parentesco migram temporariamente, acompanhando os jovens estudantes. As bolsas de estudos permitem, em regra, apenas a locação de moradias em regiões periféricas e distantes dos campi universitários. A realização de cursos e atividades no período noturno constitui uma limitação à vida acadêmica plena. São longos trajetos através da cidade em um sistema de transporte público deficitário.

Um jovem estudante indígena que residia com sua esposa e filha em uma casa compartilhada com demais famílias indígenas, porém pertencentes a etnias diferentes, relatou que durante os longos períodos de atraso nos pagamentos das bolsas de permanência era comum se ver obrigado a sair de casa de madrugada, por volta das 5 horas da manhã, e caminhar a pé até a universidade para o início das aulas às 07h30min. Os colegas de sala de aula desconheciam a situação e muitos, 
inclusive, já possuíam seus veículos automotores, presenteados pelos pais. Ao ser indagado sobre sua origem indígena por um professor da área de meio ambiente, durante a leitura em ordem alfabética dos nomes dos estudantes para verificação diária da lista de presenças, o jovem foi surpreendido com uma admoestação pública proferida pelo professor: - "Com todo o respeito ao colega, porém quero declarar que sou contrário às políticas de cotas para o ingresso de estudantes indígenas nesta universidade. Não podemos resolver os problemas da escola pública brasileira dessa forma!”.

Nenhum colega apresentou qualquer gesto de solidariedade ou mesmo o docente buscou reparar posteriormente o constrangimento que causou. Sua identidade havia sido revelada coletivamente e se sentia sozinho. Não encontrava interlocutores na turma para realizar as atividades acadêmicas. A opção pela transferência para um novo curso na mesma área de conhecimento, poucos meses depois, se revelou acertada. No segundo curso, afortunadamente, o estudante enfim encontrou um ambiente cotidiano mais favorável, em um projeto curricular diferenciado, obtendo acolhimento, reconhecimento e apoio dos novos colegas. $\mathrm{O}$ estudante concluiu $\mathrm{O}$ segundo curso no prazo curricular, quatro anos depois.
Apesar da condição indígena ser critério obrigatório, devendo ser autodeclarada e validada para o efetivo acesso às vagas suplementares ofertadas para estudantes indígenas na UFPR, a manutenção dos vínculos sociais desses estudantes com suas coletividades de pertencimento durante a graduação não é tarefa fácil. Dentre as práticas afirmativas conquistadas por esses estudantes junto à administração da universidade, o edital de Mobilidade Acadêmica Indígena merece destaque.

Inserido no âmbito de um programa de mobilidade acadêmica precedente e de caráter universal vigente na universidade, sob a gestão da Pró-Reitoria de Assuntos Estudantis, o edital específico prevê recursos para fomentar o deslocamento universidade-comunidade, uma vez ao ano, embora em sua execução prevaleçam os critérios de caráter universal. Ao ser beneficiado por esse edital, um estudante indígena aplicou os recursos recebidos para viajar do litoral do Paraná, onde se localiza o campus no qual cursava a graduação na área da gestão, até sua terra indígena situada ao norte do estado do Rio Grande do Sul. O estudante optou pelo deslocamento em veículo automotor, tendo em vista que na viagem estaria acompanhado da esposa e de colega residente na mesma terra indígena. Ao retornar da viagem, se dirigiu ao departamento administrativo para a 
prestação de contas, apresentando ao servidor técnico responsável os cupons fiscais comprobatórios do pagamento de combustível e pedágios, correspondendo às datas previstas em seu relatório de viagem.

Ao ter os documentos rejeitados, após ser informado de que somente bilhetes de passagem rodoviária em ônibus convencional eram considerados documentos válidos para a prestação de contas, o estudante argumentou discretamente que optara pela aplicação do recurso em veículo automotor para que pudesse viabilizar, com o valor recebido, o deslocamento conjunto da esposa e do colega parente - isso não seria possível caso tivesse optado pela viagem de ônibus. O constrangimento e "desonra" - conforme relatou o estudante - seguiu-se na resposta em alto tom, proferida pelo agente público: 'Nosso compromisso aqui é com você, não com sua mulher ou parente! Os recursos do programa são para os estudantes da universidade, não para seus familiares!”. Sob os olhares dos demais servidores, o estudante indígena - sujeito coletivo reduzido à condição de indivíduo moderno - se retirou da sala, arcando com a dívida e a humilhação, em silêncio.

As situações narradas acima compõem, ainda que de modo fragmentário, um inventário de uma década de acompanhamento das políticas de ação afirmativa pelos autores e não constituem um registro isolado. $\mathrm{O}$ sutil e perverso campo de preconceitos contra a efetivação de direitos humanos de nova geração dentre os quais se incluem os direitos coletivos - é anotado também em obra organizada pelo intelectual indígena Gersem Baniwa, na qual observa-se, após um amplo estudo sobre as relações entre instituições de ensino superior e os povos originários que:

o preconceito pode ser sentido por parte dos colegas não indígenas, que demonstram não querer trabalhar com eles em grupo e não os incluem nas conversas. Por parte dos professores, tal situação pode ser verificada na escassa atenção fornecida e no não reconhecimento de sua identidade. Afirmaram sofrer preconceito até no transporte que os conduz da aldeia para a universidade por parte das pessoas não indígenas que também viajam ali. Referiram-se igualmente ao preconceito da universidade como instituição, apontando a falta de diálogo e de abertura para as necessidades e demandas indígenas. (CINEP, 2010:225)

Como compreender e analisar tais situações? Neste artigo, elegemos abordar os casos estudados aplicando a via interpretativa proposta pelo constitucionalista estadunidense, de origem nipônica, Kenji Yoshino (2006), da Faculdade de Direito de Yale, que pesquisa no campo dos direitos humanos as relações entre direitos civis e minorias. 


\section{Direitos civis e minorias}

No ano de 2019, para o processo de retorno às aulas, a Universidade Federal do Paraná promoveu uma campanha denominada "Recomeços são possíveis". Em seu texto, o programa esclarece que:

na volta às aulas, a UFPR recebe um grande número de novos alunos. Entre eles estão migrantes que vêm ao Brasil em busca de um recomeço. Imigrantes e refugiados que deixaram seu país para trás, em busca de melhores condições de vida. Cabe a nós, professores, alunos e técnicos, praticarmos a empatia e a gentileza (UFPR, 2019)

A coordenadora do programa observa que a campanha visa a "sensibilizar professores, servidores e estudantes para a importância do acolhimento e do olhar para o Outro". Trata-se, nesse sentido, antes de uma "iniciativa de prevenção"6, segundo seu relato.

As políticas voltadas ao ingresso e permanência de estudantes migrantes e refugiados tiveram início posteriormente àquelas direcionadas aos povos indígenas originários na UFPR. Ambas se somam às políticas de ação afirmativa para estudantes negros, com necessidades especiais,

\footnotetext{
5 http://www.ufpr.br/portalufpr/noticias/ufpr-lancacampanha-de-conscientizacao-recomecos-saopossiveis-para-abordar-acolhimento-deestudantes-migrantes-e-refugiados/ ${ }^{6}$ Idem.
}

provenientes de escolas públicas, quilombolas, oriundos de assentamentos da reforma agrária, escolas nas ilhas, faxinais etc.

É um conjunto de ações que visa a ampliar os segmentos sociais com acesso ao ensino superior. Não obstante, o cotidiano na universidade pode se revelar muito difícil para esses segmentos da população. A campanha é relevante para alertar a comunidade acadêmica na direção de uma cultura de reconhecimento às diferenças, ao caráter plural da vida social.

Segundo o jurista Kenji Yoshino (2006), vivemos em meio a um tempo em que o preconceito e a discriminação ocorrem de maneira diferente do que ocorria em tempos passados. Outrora, tais ações seriam mais claras, aplicavam-se a grupos definidos e de modo explícito: mulheres, gays, negros, indígenas, pessoas com deficiência etc. O debate sobre os direitos humanos e, especificamente, sobre os direitos civis fizeram com que muitas dessas discriminações fossem consideradas ilegais.

Nesse contexto, novas formas sutis de discriminação estão ocorrendo na contemporaneidade. Ainda segundo o autor, não é todo o grupo que é discriminado, mas sim um subgrupo que se recusa a agir segundo a expectativa da sociedade. É uma discriminação contra os negros, mas não todos, somente contra aqueles que, por exemplo, usam o cabelo de modo diferente; 
não é contra todos os estrangeiros, mas somente contra os que se recusam a parar de falar a língua nativa em público, em detrimento da língua nacional; não abrange todas as mulheres, mas aquelas que optam por não depilar o corpo, insistem em amamentar em público ou relutam em se conformar a uma expectativa de identidade feminina socialmente validada. Em todos os casos, há uma expectativa social de acobertamento da identidade, através do constrangimento de comportamentos socialmente desqualificados.

No entanto, Kenji Yoshino (2006) observa que esse acobertamento da identidade não resulta de uma ação ou estratégia consciente empreendida com um fim específico por pessoas ou instituições. $\mathrm{E}$ essa é uma das razões pelas quais o autor busca conceitos que possibilitem denominar, interpretar e analisar esse fenômeno social. Para ele não importa em que grupo social se esteja, sempre haverá um imperativo para encobrir quem se é. Nesse contexto, resta a questão: Como compreender que somos todos diferentes e simultaneamente respeitar cada diferença, cada pessoa, cada grupo social ou étnico?

Para responder a essa questão o autor resgata categorias sociológicas aportadas por Erving Goffman em seu clássico ensaio "Estigma, notas sobre a manipulação da identidade deteriorada" (GOFFMAN, 2013). Duas categorias cunhadas por Goffman são articuladas para analisar situações que Yoshino qualifica como novas formas de discriminação e preconceito.

A noção de passing poderia ser traduzida e compreendida como uma espécie de acobertamento da identidade. Passing ou acobertamento é verificável em cenas cotidianas nas quais, por exemplo, uma pessoa se esforça para agir como se fosse outra, de modo a ser acolhida e obter aceitação e reconhecimento diante de um grupo social diferente e abrangente. De modo inconsciente, a representação de si nessas cenas cotidianas envolve atitudes resultantes da pulsão vital que resiste em recair em sofrimento.

Por sua vez, a noção de covering poderia ser traduzida por encobrimento da identidade. Essa noção pode ser válida para compreender atitudes verificáveis em um estágio quando se é forçado a fazer (ou não fazer) certas coisas em público, participar (ou não) de determinadas atividades. O encobrimento também ocorre de maneira sutil, quase inconsciente. Você é aceito, desde que se enquadre em certos padrões de respeitabilidade: modo de vestir, de ser, de estar.

Ou seja, ambas as categorias estão correlacionadas ao momento quando a sociedade e suas instituições, mesmo reconhecendo e aceitando as diferenças, fazem pressão com relação ao comportamento, posicionamento, atitudes 
dos sujeitos da diversidade. Para Kenji Yoshino (2006), essas noções podem ser válidas para interpretar e problematizar situações que envolvem todas as minorias, as quais podem ser incluídas analiticamente nessas categorias, embora os casos analisados pelo autor sejam mais diretamente relacionados a cenas cotidianas de discriminação sexual e de gênero.

Uma das razões pelas quais é difícil perceber o covering ou encobrimento reside no fato de que há um ideal de simulação que impele a compreender a sociedade como se fosse uma instituição única ou total. Para o autor, as sociedades modernas concordam que as diversas formas de preconceito, discriminação e racismo são ruins. No entanto, mesmo concordando com isso, há uma expectativa de que, nas situações do cotidiano, a atitude seja universalista.

Kenji Yoshino discorre também sobre a possibilidade de ocorrer o cover reverso, quando, por exemplo, mulheres precisam encobrir sua feminilidade no ambiente do trabalho. Elas não somente estão sujeitas ao encobrimento, mas também ao que o autor denomina de encobrimento reverso. Assim como ocorre às demais minorias, é solicitado às mulheres que passem a agir como homens em seus ambientes de trabalho ou estudo, que não falem sobre os filhos, fingindo que eles são invisíveis. Se estiver grávida, a mulher precisa esconder a gravidez o máximo que puder, se tiver que sair do trabalho ou da aula por causa de um filho, deverá mentir ou ocultar o motivo. No entanto, se as mulheres se disfarçam demais, também são punidas, sendo forçadas sutil ou deliberadamente a ser mais femininas, a usar saias, maquiagem, moderar o tom de voz etc. Casos como esses caracterizam o que o autor denomina de encobrimento reverso.

Kenji Yoshino se pergunta: Como chegar a um novo patamar de direitos civis? Sobre o conceito de covering, o autor lembra que se trata de uma dinâmica diferente da discriminação direta e que a igualdade não é algo abstrato. $\mathrm{O}$ caminho para a cidadania e a democracia exigiriam, na perspectiva do autor, a ampliação das comunidades argumentativas de modo a amadurecer a ação comunicativa capaz de comportar o dissenso. Tal movimento deve transcorrer em espaços abertos ao debate público. Porém uma cultura de fato democrática, que leve os mecanismos de deliberação e amadurecimento das ideias a sério, esbarra em condicionantes históricas nacionais, tais como o autoritarismo e o machismo na tradição política contemporânea. 


\section{Considerações finais}

A relativização de estruturas de poder heteronormativas e as dificuldades em debater na esfera pública casos como os narrados nesse ensaio revelam, num primeiro momento, que as instituições necessitam aperfeiçoar suas rotinas e práticas na direção da efetivação de horizontes normativos alicerçados nos princípios filosóficos que orientam a nova classe de direitos, tais como os direitos coletivos ou direitos humanos.

Essas premissas deveriam anteceder a criação de procedimentos voltados a denominada "mediação de conflitos" a qual, se não for substantivada, com a fina percepção e responsabilização das ações que reiteram o preconceito e a discriminação, corre o risco de simplesmente formalizar e não encaminhar soluções concretas aos desafios da vida cotidiana nas instituições. Além disso, se poderia dizer que, não raro, práticas de caráter universalista, justificadas por premissas assistencialistas e orientadas por critérios genéricos de vulnerabilidade socioeconômica, são também encobridoras dos regimes autoritários que as sustentam, vigentes nas instituições em que ocorrem.

A simbiose entre autoritarismo e assistencialismo em sociedades contemporâneas constitui a antítese do pluralismo, da diversidade, do reconhecimento dos sujeitos de direitos e do acesso à justiça, em amplo sentido. Tal antítese reduz as diversas expressões dos sujeitos da diferença na cena cotidiana através de uma lente desmoralizante que induz ao encobrimento ou acobertamento identitário, sendo todas as variantes que desviem dessa expectativa, correlacionadas a supostos privilégios, benesses etc. Um caminho para a superação das contradições que reduzem a diversidade da vida a um único modo de manifestação reside potencialmente no dissenso, no exercício da cidadania afirmativa e no aprofundamento da democracia. Tal caminho, como sugere Yoshino, exigirá o aprofundamento da democracia institucional, com o aperfeiçoamento de instâncias deliberativas no sentido da qualificação da ação comunicativa.

\section{Referências bibliográficas}

AUPETIT, Sylvie Didou; ALLIONE, Eduardo Remedi. "Los olvidados: acción afirmativa de base étnica e instituciones de educación superior en América Latina. "México - DF: Juan Pablos Editor, 2009.

BOBBIO, Noberto. Igualdade e liberdade. Rio de Janeiro - RJ: Ediouro, 1996.

CARDOSO DE OLIVEIRA, Roberto. A Sociologia do Brasil Indígena. Rio de Janeiro - RJ: Tempo Brasileiro, 1972. 
CINEP. "Esboço de um perfil do estudante indígena no ensino superior no Brasil". In: LUCIANO, Gersen.; HOFFMANN, Maria Barroso. (Org.) Olhares indígenas contemporâneos. Brasília - DF: Centro Indígena de Estudos e Pesquisas, 2010, pp. 204-259.

CUNHA, Manuela Carneiro da. Índios no Brasil: história, direitos e cidadania. São Paulo - SP: Claro Enigma, 2012.

DWORKIN, Ronald. Justice for hedgehogs. Cambridge/London: Harvard University Press, 2011.

FREITAS, Ana Elisa de Castro (Org.) Intelectuais indígenas e a construção da universidade pluriétnica no Brasil: Povos Indígenas e os novos contornos do Programa de Educação Tutorial/Conexões de Saberes. Rio de Janeiro - RJ: E-papers/LACED/Museu Nacional/UFRJ, 2015a.

\section{“A Resolução 37/04-COUN e a educação superior para indígenas na UFPR”. In: ZAINKO, Maria Amélia; FREITAS, Ana Elisa de Castro; CERVI, Emerson; CUNHA, Josafá e VON DER HEYDE, R. Relatório da Comissão encarregada de avaliar os 10 anos de implantação do Plano de Metas de Inclusão Racial e Social na UFPR. Curitiba: PROGRAD/UFPR, 2015b, pp.5 - 27.}

FREITAS, Ana Elisa de Castro; HARDER, Eduardo. "Da política de estado ao estado da política, panorama de uma década de ensino superior indígena no Paraná”. In: BERGAMASCHI, Maria Aparecida; NABARRO, Edilson e BENITES, Andréa. (Org.) Estudantes Indígenas no Ensino Superior: uma abordagem a partir $d a$ experiência da UFRGS. Porto Alegre - RS: Editora da Universidade, 2013a., pp. 169-182.
"Entre equidade e assimetria de poder: uma análise da implementação de políticas afirmativas de educação superior indígena no Brasil. Século XXI" - Revista de Ciências Sociais. UFSM, Vol. 3, n. 1, Jan./Jun. 2013b.

\section{. "Os Povos Indígenas no ensino} superior e os caminhos para a efetivação da justiça e do bem viver". In: FONSECA, Ana Carolina da Costa e; LEIVAS, Paulo Gilberto Cogo (Org.). Direitos humanos e saúde: volume 1. Porto Alegre - RS:

Editora da UFCSPA, 2018, pp. 303-319.

" "Sobreviver na diferença": o olhar dos estudantes indígenas e suas contribuições ao II Encontro de Educação Superior Indígena no Paraná”. In: NOVAK, Maria Simone Jacomini; et alli .(Orgs.) Educação Superior Indígena no Paraná. Maringá - PR: EDUEM, 2010, pp. 77-91.

GOFFMAN, Erving. Estigma: notas sobre a manipulação da identidade deteriorada. 4.ed. Tradução Márcia Bandeira de Melo Leite Nunes. Rio de Janeiro - RJ: LTC, 2013.

A representação do eu na vida cotidiana. $10^{a}$. ed. Tradução Maria Célia Santos Raposo. Petrópolis - RJ: Editora Vozes, 2002.

HONNETH, Axel. Luta por reconhecimento: a gramática dos conflitos sociais. Tradução Luiz Reppa. São Paulo SP: Editora 34, 2003.

INGOLD, Tim. Estar Vivo: ensaios sobre movimento, conhecimento e descrição. Tradução Fábio Creder. Coleção Antropologia. Petrópolis - RJ: Vozes, 2015.

JACINTO DA ROSA, Douglas. Gestão socioambiental e territoral de terras 
indígenas sob uma perspectiva Kaingang: um ensaio (auto) etnográfico em Re Kuju Campo do Meio, Bacia Hidrografica do Alto Uruguai, atual estado do Rio Grande do Sul. Trabalho de Conclusão do Curso de Bacharelado em Gestão Ambiental, Matinhos - PR: UFPR/LITORAL, 2015.

NERES, Irosângela Correa. Sentimentos e sentidos das experiências vividas por estudantes indígenas na UFPR. Trabalho de Conclusão de Curso em Pedagogia. Setor de Educação. Curitiba - PR: UFPR. Disponível em:

https://drive.google.com/file/d/0B3pIPIL_V

1DYUFuTzVQOXJBRzhKSVdIWHNxM2 pGUUFEcEVj/view. Acesso em: 20/08/2018.

PALADINO, Mariana; ALMEIDA, Nina Paiva. Entre a diversidade e a desigualdade: uma análise das políticas públicas para a educação escolar indígena no Brasil dos governos Lula. Rio de Janeiro - RJ: Contra Capa/LACED/Museu Nacional/UFRJ, 2012.

SANDEL, Michael J. Justiça: o que é fazer a coisa certa. Tradução Heloisa Matias e Maria Alice Maximo. Rio de Janeiro - RJ: Civilização Brasileira, 2011.

VIVEIROS DE CASTRO, Eduardo. "Os pronomes cosmológicos e o perspectivismo ameríndio." Mana vol. 2 no. 2 Rio de Janeiro. Oct. 1996.

YOSHINO, Kenji. Covering: the hidden assault on our civil rights. New York: Random House, 2006.

ZONINSEIN, Jonas; FERES Júnior, João. "Ação afirmativa no ensino superior brasileiro." Belo Horizonte - MG: Editora UFMG; Rio de Janeiro: IUPERJ, 2008. 